\title{
In vitro adhesion properties of Shiga toxin-producing Escherichia coli isolated from cattle, food, and humans
}

\section{Nathalie Pradel ${ }^{1+}$, Lucie Etienne-Mesmin ${ }^{1,2}$, Jonathan Thévenot ${ }^{1,2}$, Charlotte Cordonnier $^{1,2}$, Stéphanie Blanquet-Diot ${ }^{2}$ and Valérie Livrelli ${ }^{1,3}$ *}

\author{
Centre de Recherche en Nutrition Humaine Auvergne, M2iSH, 'Microbes, Intestin, Inflammation et Susceptibilité de I'Hôte' UMR INSERM/Université \\ d'Auvergne U1071 USC-INRA 2018, Clermont Université - Université d'Auvergne, Clermont-Ferrand, France \\ 2 Centre de Recherche en Nutrition Humaine Auvergne, EA-4678 CIDAM, 'Conception Ingénierie et Développement de I'Aliment et du Médicament', Clermont \\ Université - Université d'Auvergne, Clermont-Ferrand, France \\ ${ }^{3}$ Unité de Recherche M2iSH, Faculté de Pharmacie, CHU Clermont-Ferrand, Service Bactériologie Mycologie Parasitologie, Clermont-Ferrand, France
}

\section{Edited by:}

Christina Maria Joseph Elisabeth Vandenbroucke-Grauls, VU University Medical Center, Netherlands

Reviewed by:

Polly Leung, The Hong Kong Polytechnic University, Hong Kong

Kerry Cooper, United States

Department of Agriculture -

Agricultural Research Service, USA

*Correspondence:

Valérie Livrelli, Unité de Recherche M2iSH, Faculté de Pharmacie, CHU

Clermont-Ferrand, Service

Bactériologie Mycologie Parasitologie,

28 Place Henri-Dunant, 63001

Clermont-Ferrand, France

e-mail: valerie.livrelli@udamail.fr

${ }^{\dagger}$ Present address:

Nathalie Pradel, Aix Marseille

Université, IRD, CNRS, Mediterranean

Institute of Oceanography, UM 110,

13288 Marseille, France
Shiga toxin-producing Escherichia coli (STEC) are able to cause serious illnesses ranging from diarrhea to hemorrhagic colitis and hemolytic-uremic syndrome (HUS). These bacteria colonize the digestive tract of humans and produce Shiga-toxins, which are considered to be essential for virulence and are crucial in lethal infection. Colon colonization is supposed to be a determinant step in the development of the infection, but the virulence traits that mediate this step are unclear. We analyzed the ability of 256 STEC strains belonging to seropathotype $A$ (the most virulent $\mathrm{O} 157: \mathrm{H} 7$ serotype) to seropathotype $\mathrm{E}$ (not involved in human disease) to adhere to HEp-2, HCT-8, and T84 cell lines. Of the 256 STEC tested most $(82 \%)$ were non-adherent in our assays. The adhesion levels were globally low and were not related to pathogenicity, although the highest levels were associated to O26:H11 and O103:H2 strains of seropathotype B lassociated with HUS but less commonly than serotype 0157:H7), possessing both the eae and tox $B$ genes.

Keywords: STEC, cell lines adhesion, seropathotype, eae, toxB

\section{INTRODUCTION}

Shiga toxin (Stx)-producing Escherichia coli (STEC) can be associated with human diseases, ranging from uncomplicated diarrhea to hemorrhagic colitis (HC) and hemolytic-uremic syndrome (HUS; Hussein, 2007). Enterohemorrhagic E. coli (EHEC) constitute a subset of pathogenic STEC that also contain the LEE (Clements et al., 2012). The most prominent serotype within the EHEC group is O157:H7 (Paton and Paton, 1998). STEC food-borne infections, either outbreaks or sporadic cases, appear worldwide.

As example, an outbreak with 1000s cases of food-borne illness has been caused by an emerging atypical O104:H4 Stx-producing pathogen in 2011 in Germany (Bielaszewska et al., 2011; Frank et al., 2011; Clements et al., 2012; Trachtman et al., 2012). Several studies have shown a high prevalence of STEC belonging to a wide range of serotypes in animals and food products (Pradel et al., 2000; Beutin, 2006; Hussein, 2007). However, only a limited number of serotypes have been associated with human disease, among which O157:H7 is predominant (Rangel et al., 2005). The association of serotypes with disease of varying severity in humans, and with outbreaks or sporadic disease, has led to the proposal that STEC be classified into five seropathotypes: A (the most virulent O157:H7 serotype), B (associated with outbreaks and HUS but less commonly than serotype O157:H7), C (associated with sporadic HUS but not typically with outbreaks), D (associated with diarrhea but not with outbreaks or HUS), and E (serotypes that have not been involved in disease in humans; Karmali et al., 2003). STEC colonize the digestive tract of humans and produce Stx1 and/or Stx2 which are essential for virulence. Different combinations of potential pathogenicity factors have been observed in clinical isolates, in addition to the production of Stx (Paton and Paton, 1998; Girardeau et al., 2005; Pradel et al., 2008). However, the known virulence factors do not allow differentiation of STEC strains with a high pathogenic potential from their counterparts of lesser clinical significance.

The terminal ileum and the colon are supposed to be the main sites of EHEC colonization in humans, whereas in cattle, the terminal recto-anal junction is thought to be the primary site of colonization of the bovine gastrointestinal tract (Naylor et al., 2003; Chong et al., 2007; Mahajan et al., 2009). Some STEC strains adhere to epithelial cells in a histopathological lesion pattern known as attaching and effacing (A/E) adhesion, first described in enteropathogenic E. coli (EPEC), characterized by the effacement of microvilli and the formation of actin pedestals, and involving intimin EaeA (Hayward et al., 2006). In vitro adherence of STEC strains has been examined using different epithelial cell lines under 
a range of experimental conditions. The "gold standard" method was originally described to analyze virulence properties of E. coli strains involved in diarrhea (Knutton et al., 1989). The HEp-2 or HCT-8 cell assay is considered as a suitable model to study A/E lesions in STEC (McKee and O'Brien, 1995). The human intestinal T84 cell line is also used for studies of the adhesion properties since these cells resemble human colonic epithelial cells, which are thought to be the in vivo target cells for STEC infection (Winsor et al., 1992; Li et al., 1999). However, not all the pathogenic STEC strains are able to adhere in an A/E mechanism. Thus, the virulence traits that mediate STEC colonization are not fully understood.

In this study, the adhesion properties of a collection of 256 STEC strains (belonging to seropathotypes A to E), isolated from humans, foods, or animals, were analyzed using in vitro adhesion tests to human epithelial cell lines (HEp-2, HCT-8, T84) and relationships between adhesion, virulence factors, and pathogenicity were investigated.

\section{MATERIALS AND METHODS BACTERIAL STRAINS}

The distribution according to origin and seropathotype of the 256 STEC isolates tested in this study is given in Table $\mathbf{1}$. Among the 256 STEC strains, 32 were isolated from patients suffering from HUS or $\mathrm{HC}, 187$ were isolated from bovine feces, 26 from food samples, and 11 from asymptomatic children (Pradel et al., 2000, 2002). EHEC O157:H7 strains EDL933 (ATCC 43895) and 86-24 (Tarr et al., 1989), and EPEC strain E2348/69 were used as references strains. E. coli strain K-12 C600 was used as a negative control. Bacteria were stored in Luria broth (LB), with $10 \%$ glycerol at $-80^{\circ} \mathrm{C}$. Unless otherwise stated, the strains were grown overnight at $37^{\circ} \mathrm{C}$ in $\mathrm{LB}$.

\section{CELL LINE AND CELL CULTURE}

The human laryngeal epithelioma cell line HEp-2 (ATCC CCL-23; American Type Culture Collection, USA), the human ileocecal carcinoma cell line HCT-8 (ATCC CCL-244), and the human colonic carcinoma cell line T84 (ATCC CCL-248) were used for investigating STEC adhesion profiles. The three cell lines were grown with

Table 1 | Number of strains analyzed in this study according to origin and seropathotype.

\begin{tabular}{lllllllll}
\hline & \multicolumn{1}{c}{ Seropathotypes } \\
\cline { 2 - 8 } & & A & B & C & D & E & ND & Total \\
\hline \multirow{3}{*}{ Origin } & Number of serotypes & 1 & 2 & 19 & 22 & 49 & - & 93 \\
& Patients (HUS, HC) & 10 & 8 & 10 & 0 & 0 & 4 & 32 \\
Bovine feces & 1 & 2 & 57 & 37 & 79 & 11 & 187 \\
Food & 2 & 0 & 6 & 4 & 11 & 3 & 26 \\
Asymptomatic children & 0 & 2 & 0 & 9 & 0 & 0 & 11 \\
\hline \multirow{2}{*}{ Total } & 13 & 12 & 73 & 50 & 90 & 18 & 256
\end{tabular}

HUS, hemolytic-uremic syndrome; HC, hemorrhagic colitis; ND, not determined.
DMEM supplemented with 10\% fetal bovine serum (FBS; Lonza) and antibiotics (2\% penicillin G-streptomycin-amphotericin B) at $37^{\circ} \mathrm{C}$, in an atmosphere of $5 \% \mathrm{CO}_{2}$. The T84 cells were differentiated by growing five days in 24 -well plates coated with collagen I (Roche). About $10^{6}$ viable cells were used for each bacterial infection in 24-well plates.

\section{ADHESION ASSAYS}

The bacterial strains were grown for $3 \mathrm{~h}$ (exponential growth phase) or $18 \mathrm{~h}$ (late growth phase) at $37^{\circ} \mathrm{C}$ before infection, in LB or in Cell Culture Medium (CCM) with 50\% HAM-50\% DMEM. Bacteria were harvested by centrifugation at $7000 \times g$ for $10 \mathrm{~min}$ and suspended in CCM in the presence of $1 \% \alpha-\mathrm{D}-$ mannoside to a final concentration of $10^{8} \mathrm{CFU}$ per $\mathrm{ml}$, which was checked by plating on LB agar for each inoculum. The culture cells were washed three times with $\mathrm{PBS}$ pH 7.4 and then infected with $10^{8}$ bacteria for $3 \mathrm{~h}$ at $37^{\circ} \mathrm{C}$ at a multiplicity of infection (MOI) of 100. After $3 \mathrm{~h}$, non-adherent (NA) bacteria were removed from the cells by three washes with PBS. Bacterial adherence patterns were examined with phase-contrast microscopy after Giemsa staining. For quantitative adherence assays, the cells were gently scraped off with $1 \%$ triton X-100 (Sigma) in PBS, and serial 10 -fold dilutions were plated overnight at $37^{\circ} \mathrm{C}$ onto Luria agar plates. Each experiment was repeated at least three times. Variations in the level of F-actin in HEp-2 and HCT-8 cells were estimated by fluorescence actin staining (FAS) assay (Knutton et al., 1989). Scanning electron microscopy (SEM) was performed as previously described by Xicohtencatl-Cortes et al. (2007).

\section{DETECTION OF GENES ASSOCIATED WITH ADHESION}

All STEC isolates were analyzed for the presence of genes encoding for EaeA, EfaI, ToxB, LpfA, Saa, East1, EspP, and Iha. The corresponding eae, efal, toxB, lpf, saa, ast $A$, esp $P$, and iha genes were amplified using primers listed in Table 2 . The presence of the genes was determined directly by PCR and/or by colony blot hybridization using probes labeled with $\alpha-{ }^{32} \mathrm{P}-\mathrm{dCTP}$, as described previously (Pradel et al., 2002).

\section{STATISTICAL ANALYSIS}

The data were analyzed with Epi Info version 6.02 by the $\chi^{2}$ test, except for the variable needing a two-tailed Fischer exact test. The Student $t$-test for unpaired data was used at the $5 \%$ level of significance for the comparison of values.

\section{RESULTS \\ QUANTITATIVE ADHESION OF 17 STEC STRAINS TO THE T84 CELL LINE}

Different bacterial growth phases (exponential growth phase vs. late-log phase), and types of bacterial culture media (LB vs. $\mathrm{CCM}$ ) were tested in preliminary infection experiments on the T84 human colonic carcinoma cell line. These assays were performed with two virulent STEC strains (O157:H7 strain EDL933 and O91:H21 strain CH014), the EPEC reference strain (E2348/69) as a positive control, and the E. coli strain K-12 C600 as a negative control (Figure 1). The best adhesion levels were obtained with strains grown for $3 \mathrm{~h}$ in CCM. For further quantitative experiments, we thus chose to incubate the bacteria for $3 \mathrm{~h}$ at $37^{\circ} \mathrm{C}$ 
Table 2 | Primers used for genes targeting and proportion of positive strains.

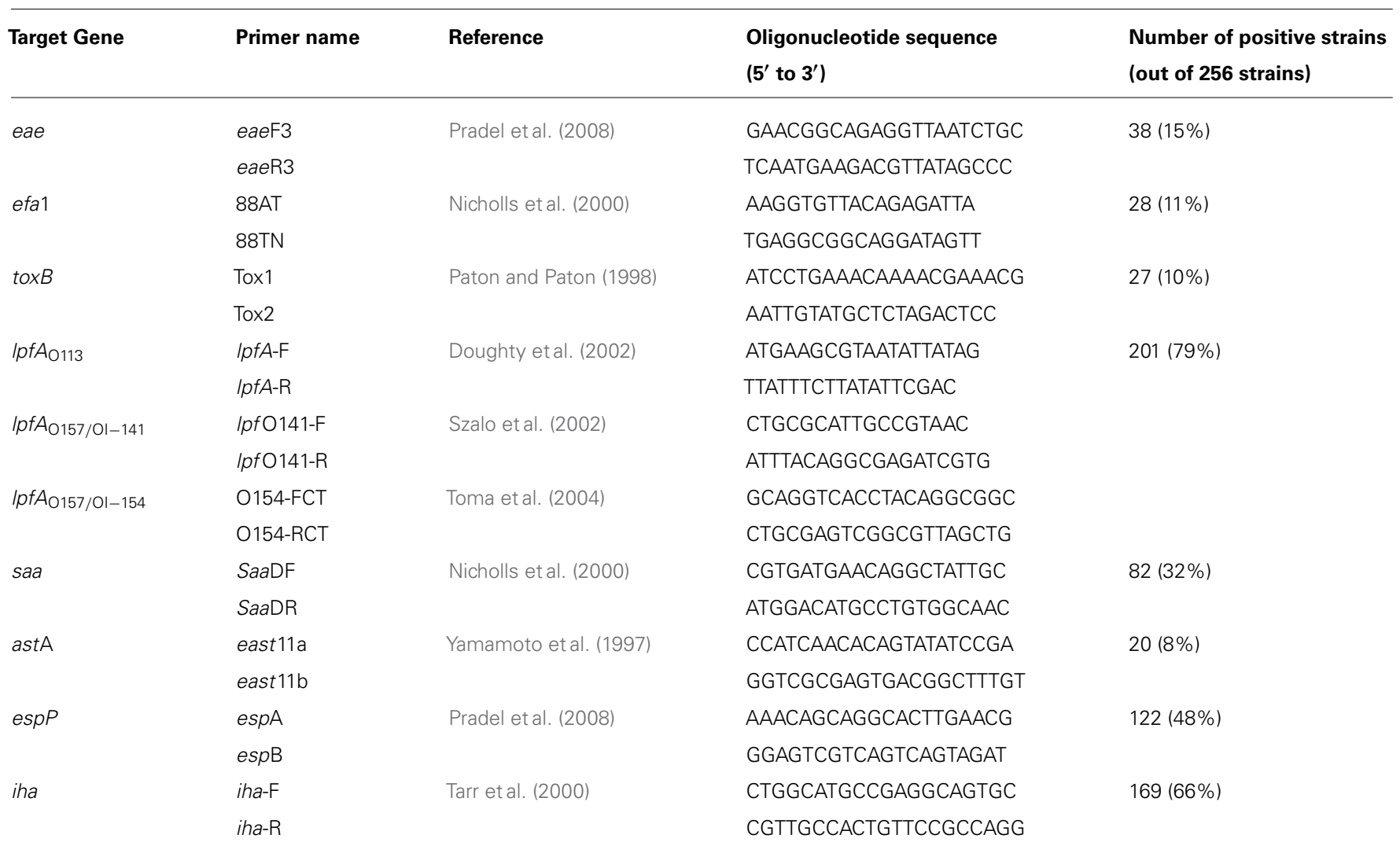

in CCM before infection. Quantitative experiments, performed on 17 STEC strains isolated from human cases, indicated that the number of bacteria adhering to the T84 cells was between $2.4 \times 10^{3}$ and $4.4 \times 10^{5} \mathrm{CFU} /$ well (Figure 2A). The number reached $2 \times 10^{6} \mathrm{CFU} /$ well for the EPEC reference strain, indicating that STEC adhered to very low levels compared to the EPEC strain, and just above the level of the negative control C600. Adherence patterns were investigated after staining with Giemsa and by SEM observations. The STEC strains adhered sparsely, whereas the EPEC formed micro-colonies (Figure 2B).

\section{ADHESION PROPERTIES OF 256 STEC TO THE HCT-8 AND HEP-2 CELL LINES}

Since very low levels of adhesion were observed with the pathogenic STEC tested on T84 cells, we chose to analyze the 17 STEC strains and 239 additional STEC strains of diverse origins on two cell lines commonly used for in vitro adhesion assays: HCT-8 (from human ileocecal carcinoma), and HEp-2 (from human larynx carcinoma) cell lines (Figure 3). We considered as adherent the strains adhering to at least one of the two cell lines. Adhesion to HCT- 8 or HEp-2 showed few strains efficiently adhering over a $3 \mathrm{~h}$ course of infection: among the 256 STEC strains, 209 (82\%) were considered as NA; (i.e., less than 1 bacterium per cell; Figure $3 \mathbf{A}$ ). Only $18 \%(47 / 256)$ of the strains adhered to at least one of the cell lines. Among them, 31 adhered both to HEp-2 and to HCT-8.

The great majority of STEC strains were NA whatever the seropathotype (A: 61\% NA, C: 84\% NA, D: 84\% NA, E: 91\% NA), except for the seropathotype B for which all the strains tested were adherent (Figure 3B). The adherent strains belonging to seropathotype A were associated to a low level of adhesion $(+, 1$ to 5 bacteria per cell; Fisher, $P=0.01$ ), and the seropathotype $B$ was associated to the higher level of adhesion $(+++$, more than 20 bacteria per cell; Fisher, $P=0.002$; Figure 3B; Table 3). Indeed, among the 39 STEC adhering to HCT-8, 15 presented an enhanced adherence ( $\geq 20$ bacteria per cell), including six of seropathotype B (four O103:H2 and two O26:H11), and one of seropathotype A (the O157:H7 strain isolated from bovine feces). Nine strains exhibited an enhanced adherence $(\geq 20$ bacteria per cell) to HEp-2 cells. These nine adhering strains were all nonO157:H7 and included two O103:H2 strains of seropathotype B isolated from bovine feces.

\section{ASSOCIATION BETWEEN ADHESION PROPERTIES AND GENES ENCODING FOR ADHESION FACTORS}

Data regarding the presence of genes eae, efal, toxB, $\operatorname{lpf}$, saa, ast $A$, esp $P$, and iha are given in Tables 2 and 3. Among the 256 STEC strains, $38(15 \%)$ were eae-positive (possessed the gene encoding for intimin), including all the STEC belonging to the seropathotypes A (13) and B (12). Twenty-two of these adhered either to HCT- 8 and/or to HEp-2 cells, but most (13 of 22) adhered at a low level ( 1 to 5 bacteria/cell), and only 17 were clearly FAS-positive by the fluorescent actin staining assay. Overall, the presence of eae was associated with adhesion (Fisher, $P<0.00000001$ ), and a strong association was observed between FAS-positive isolates and 


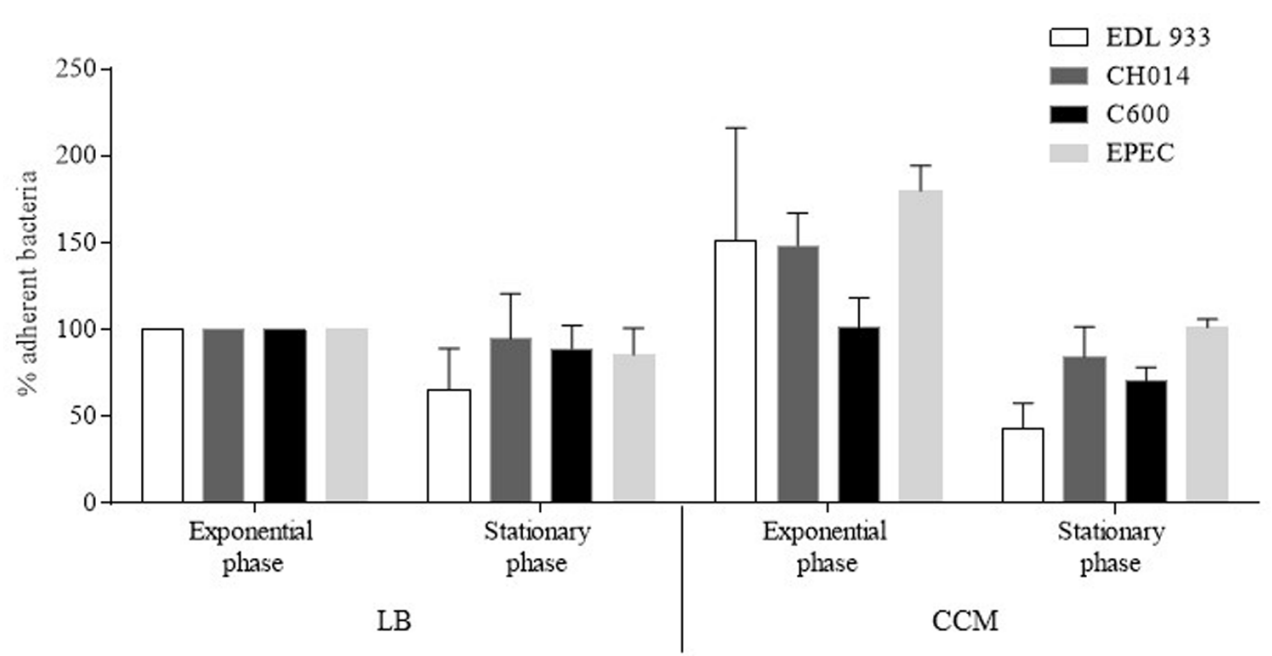

FIGURE 1 | Determination of experimental conditions for bacterial adherence of Escherichia coli strains to human colonic carcinoma T84 cells. Cells were infected with bacteria grown for $3 \mathrm{~h}$ (exponential growth phase) or $18 \mathrm{~h}$ (stationary growth phase), in Luria Bertani Broth (LB) or in Cell Culture Medium (CCM), at $37^{\circ} \mathrm{C}$ before infection. The cells were then washed, treated with Triton X-100, and the recovered adherent bacteria were diluted and plated for colony forming unit counting. Results are expressed as percentage of adherent bacteria, relative to adherent bacteria obtained after a 3 h growth in LB taken as 100\%. EDL933: EHEC 0157:H7; CH014: non-O157 STEC; C600: K-12 E. coli; E2348/69: EPEC. All assays were performed independently at least three times. Results are means \pm SEM of bacteria adhering to T84 cells. belonging to seropathotype $\mathrm{B}$ (Fischer, $P<0.0000001$ ), or isolation from a human with or without disease (Fischer, $P=0.00002$ ). The gene efal, associated to the eae gene and encoding for EHEC factor for adherence, was detected in 28 eae-positive strains $(11 \%$ of the STEC).

Only 27 of 256 STEC (10\%) were toxB positive: 17 adhered to HEp-2 and/or HCT- 8 cells, and belonged to A or B seropathotype. An association was established between the tox $B$ gene and adhesion (Fisher, $P<0.00000001$ ).

Among the 256 strains, 201 (79\%) were positive for the $\operatorname{lpf}$ gene encoding long polar fimbriae subunit A. Thirty three of the 47 adherent strains were positive for $l p f_{\mathrm{O} 157}, l p f_{\mathrm{O} 113}$, or $l p f_{\mathrm{O} 91}$. operon. Regarding saa, encoding the STEC autoagglutinating adhesin, 82 strains (32\%), belonging to the less virulent seropathotypes C, D, E, were positive, of which 11 were adherent. Regarding ast $A$, encoding the East1 enteroaggregative heat-stable toxin 1, only 20 of the 256 STEC ( $8 \%$ ) belonging to the seropathotypes $\mathrm{D}$ and $\mathrm{E}$ were positive, including 3 adherent isolates. Among the 256 strains, 122 (48\%) were positive for the autotransporter EspP, shown to be involved in the formation of macroscopic rope-like fibers (Xicohtencatl-Cortes et al., 2010). Thirty-one adhered to HEp-2 and/or HCT-8 cells. Finally, 169 strains (66\%) were positive for the gene encoding for Iha (a protein that confers adherence similar to Vibrio cholerae $\operatorname{IrgA}$ ), of which 21 were adherent. No association was established between adhesion or seropathotype and the presence of the $l p f$, saa, astA, efal, espP, or iha genes.

\section{DISCUSSION}

Shiga toxin-producing E. coli strains are an important cause of diarrheal and renal diseases in humans. They are associated with colonic pathology, and are considered as colonic pathogens, but the intestinal colonization process is still not well defined. In the absence of a suitable animal model for STEC infection that reproduces the typical human disease from the initial step of colonization to HUS (Mallick et al., 2012), adherence to epithelial cell lines was expected to mimic the in vivo situation. In this study, we analyzed the adhesion properties of a collection of 256 STEC strains isolated from cattle, food, and humans, using the intestinal epithelial cell lines HCT-8 (from human ileocecal carcinoma), T84 (from human colonic carcinoma), and the HEp-2 cells from human larynx carcinoma. More than half (51\%) of the strains of human origin (including patients and asymptomatic children) were adherent, while one third (34\%) of the STEC isolated from food, and only $8 \%$ of the cattle strains were found to adhere. The strains belonged to the five seropathotypes A (most virulent) to E (not involved in human disease), described according to disease severity in humans, and to outbreaks or sporadic diseases (Karmali et al., 2003). Among the 256 STEC, the seropathotype $\mathrm{B}$ was significantly associated with the highest adherent strains on the HEp-2 or HCT- 8 models. Our study revealed that, among the 47 adhering strains, 16 adhered only to HEp-2 or HCT-8, indicating that HEp-2 cells, widely used to explore adhesion of intestinal pathogenic E. coli might lack specific receptors. On the T84 model, EHEC O157:H7 strains (A seropathotype) adhered significantly more than those belonging to other serotypes, but the levels of adhesion observed were low. Interestingly, a high level of adhesion was not always associated with pathogenicity (assessed by the seropathotype): among the 18 STEC exhibiting the highest level of adhesion to HEp-2 and/or HCT- 8 cells, eight belonged to the seropathotypes $\mathrm{D}$ and $\mathrm{E}$. It would be interesting to test the highly adherent strains in a suitable in vivo model to determine their virulence, since they might represent emerging pathogens. The O104:H4 outbreak in Germany in 2011 highlighted the danger of such emerging pathogens, the O104:H4 


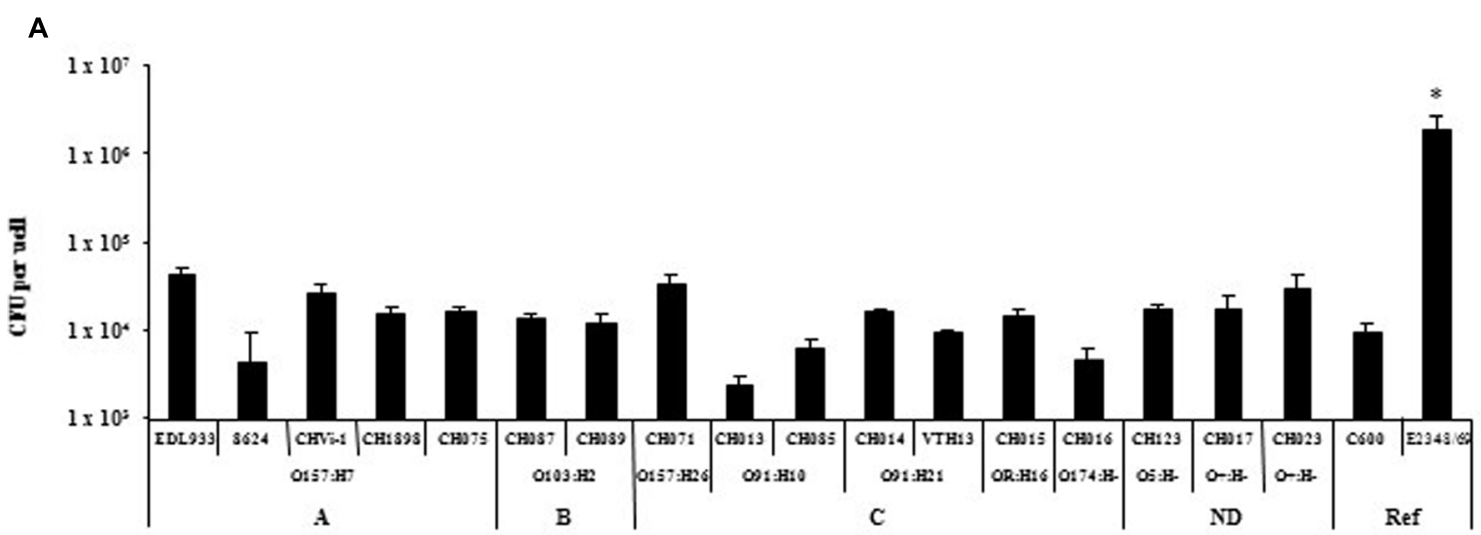

B
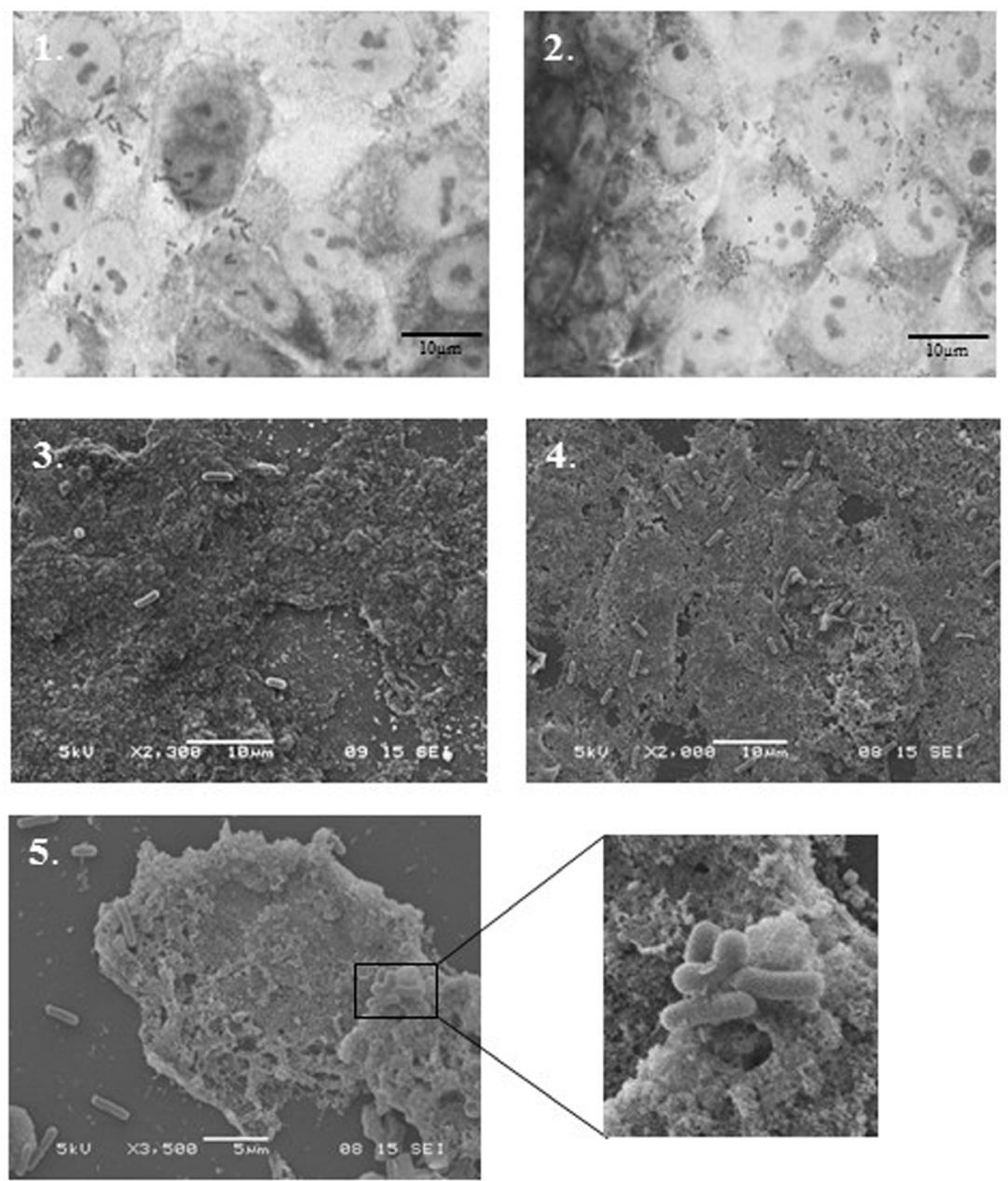

FIGURE 2 | Adhesion of STEC strains to T84 cells line. (A) Quantitative adhesion of 17 STEC strains on the human colonic carcinoma cell line T84. Strains were grown to exponential growth phase at $37^{\circ} \mathrm{C}$ in $\mathrm{CCM}$ before infection. All assays were performed independently at least three times. Results are means $\pm S D$ of bacteria adhering to T84 cells in CFU/well for the replicate experiments. A, seropathotype A; B, seropathotype $B$; $C$, seropathotype $C$; ND, seropathotype not determined; Ref, reference strains. * The level of adhesion of EPEC E2348/69 strain was significantly different from all other strains tested $(p<0.01)$. (B) Adhesion pattern of EHEC 0157:H7 (EDL933) strain (1, 3) and EPEC (E2348/69) strain (2, 4, and 5) stained with Giemsa (1,2), or after scanning electron microscopy (SEM) analysis $(3,4$, and 5$)$. Scale bar $=10 \mu \mathrm{m}$ for Giemsa and SEM, Magnification $\times 2,300$ (3), $\times 2,000$ (4), $\times 3,500(5)$ and $\times 10,000$ (enlarged box). 


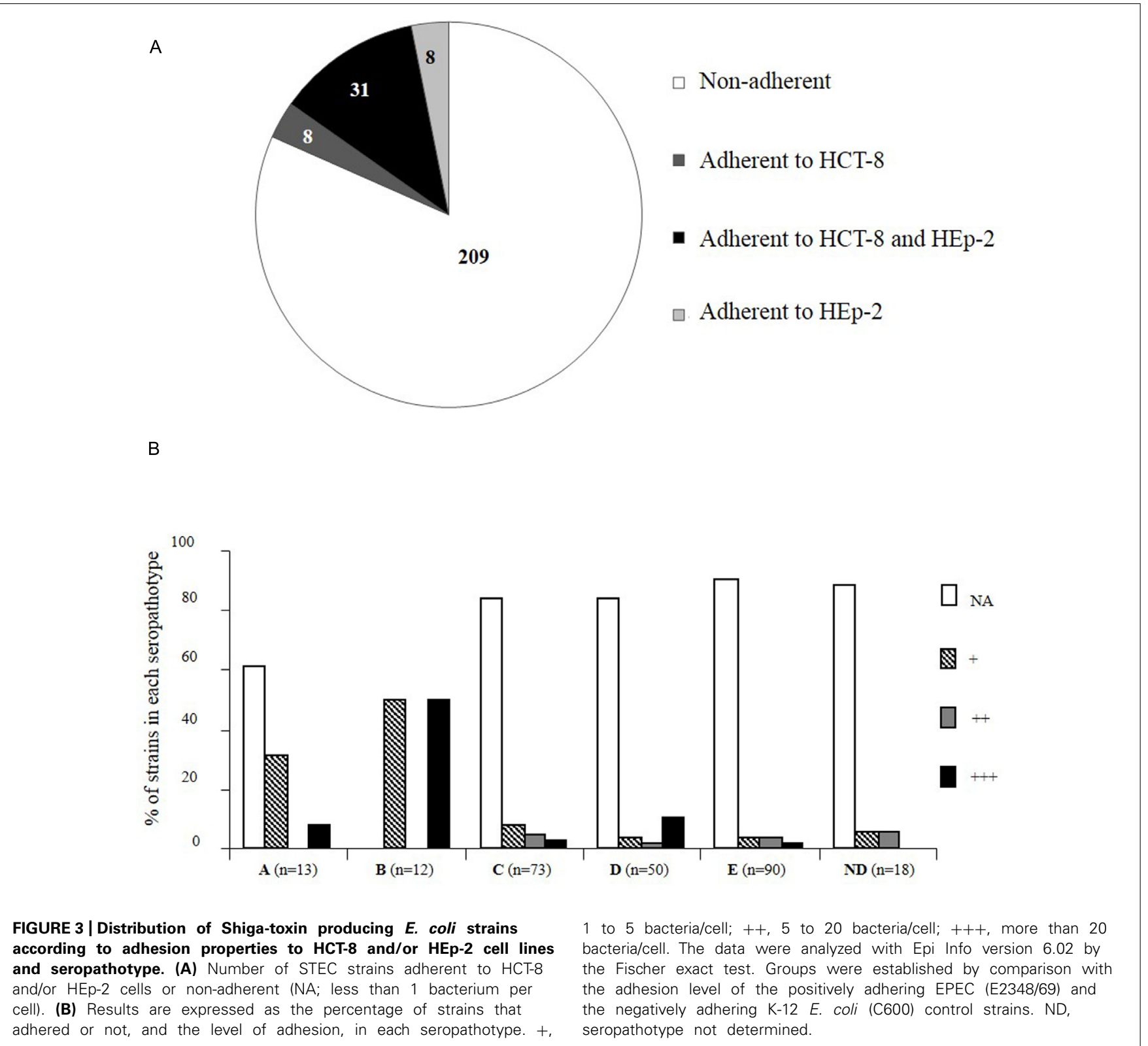

strain possessed enteroaggregative adhesion factors that made it particularly virulent.

Studies evaluating the survival of an E. coli O157:H7 strain in simulated in vitro models of human digestive tract revealed bacterial growth and multiplication in the distal parts of the small intestine, and a progressive elimination of the pathogen in the colon (Etienne-Mesmin et al., 2011b; Thevenot et al., 2013). In human and bovine small intestinal xenografts, a large number of EHEC was also detected in the small intestinal lumen, but bacteria did not attach to the epithelium (Golan et al., 2011). The same study revealed poor bacterial growth associated with the formation of A/E lesions in human colon xenografts (Golan et al., 2011). In this study, we observed low levels of adhesion on colonic derived cells, in accordance with studies conducted using human intestinal IVOC, where a preferential tropism of EHEC for the follicle-associated epithelium (FAE) overlying ileal Peyer's patches (PPs), associated with a lack of colonic adhesion has been shown (Phillips et al., 2000; Fitzhenry et al., 2002; Chong et al., 2007). The PPs-rich distal ileum may represent the initial site of EHEC adhesion, from where bacteria would either spread to other regions of the gut, or translocate through $\mathrm{M}$ cells to underlying macrophages, which may be the first step in EHEC translocation and subsequent toxin transport across the intestinal barrier (Etienne-Mesmin et al., 2011a).

Several surface proteins and fimbriae structures have been described as putative adherence factors in STEC (Nicholls et al., 2000; Tarr et al., 2000; Fitzhenry et al., 2002, 2006; Toma et al., 2004; Cergole-Novella et al., 2007; Torres et al., 2007; Mahajan et al., 2009; Xicohtencatl-Cortes et al., 2009, 2010). Among them, intimin EaeA might play a role in tissue tropism, with intimin 


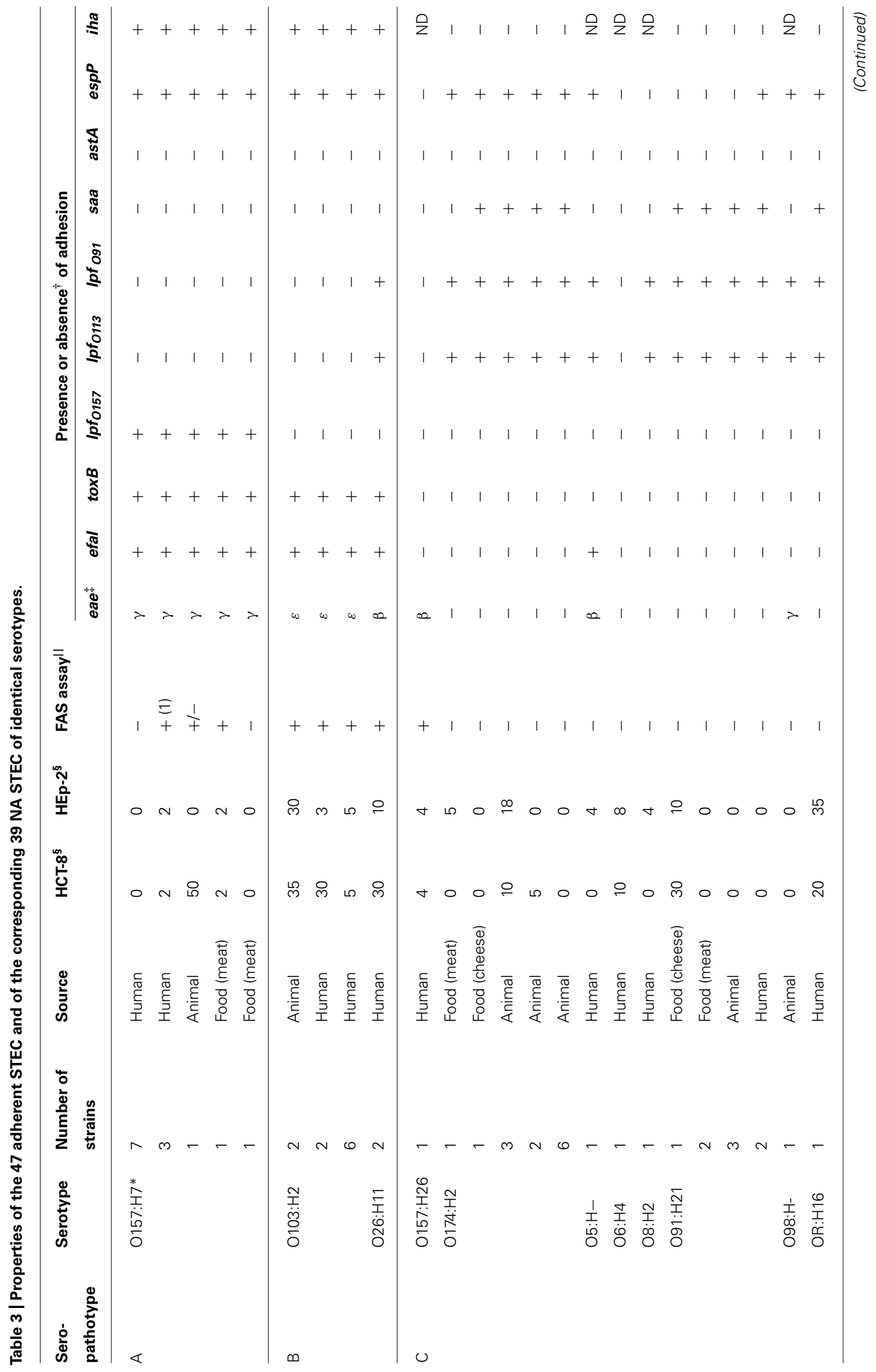




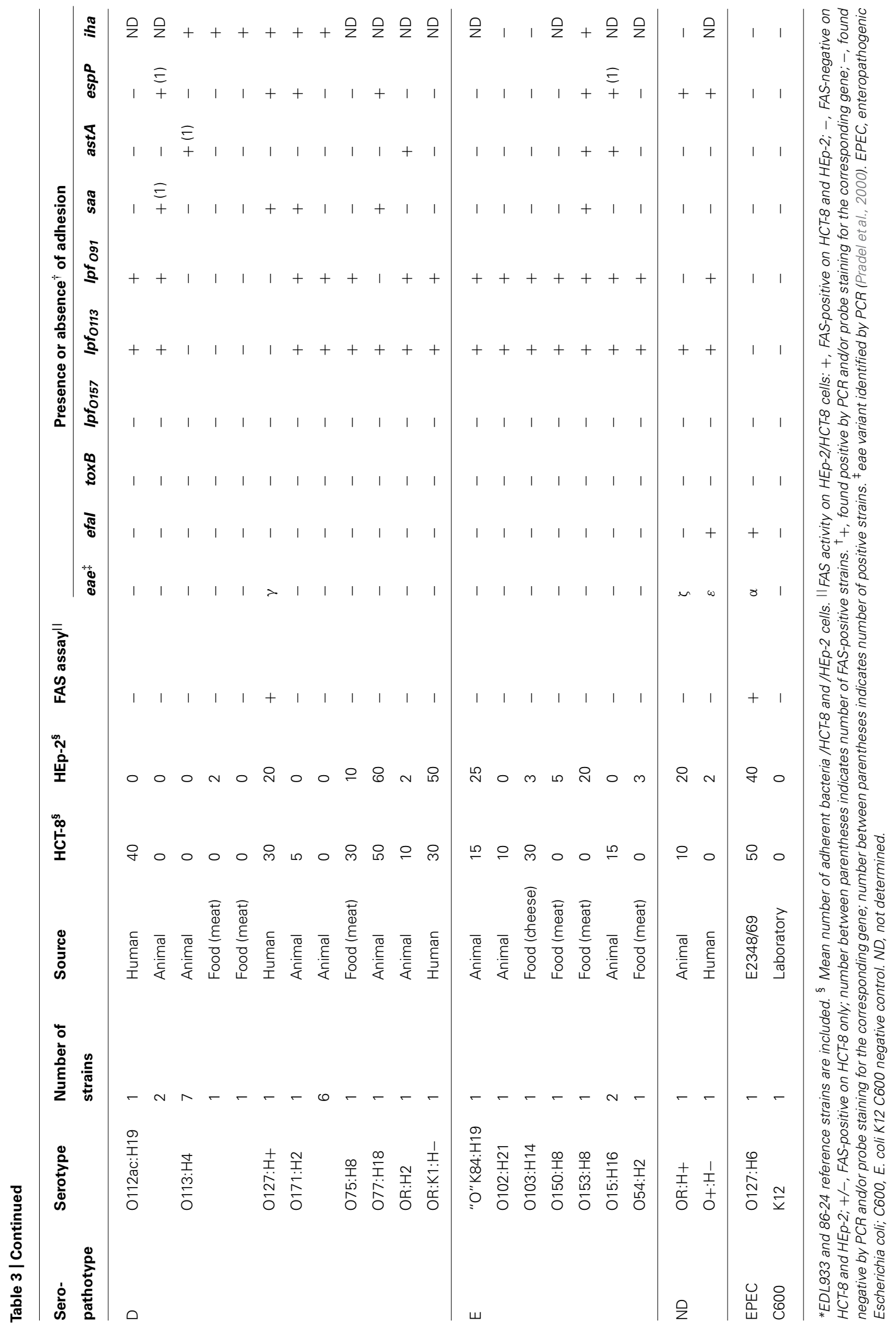


gamma appearing to restrict colonization of O157:H7 strains to human FAE (Fitzhenry et al., 2002). In our study, in addition to the eae gene, the toxB gene was clearly associated with adhesion to HEp-2, HCT-8, and T84 cell lines and isolation from humans. Taken together, adhesion levels were globally low among the 256 STEC tested and the $e a e^{+}$tox $B^{+}$STEC of seropathotype $\mathrm{B}$ presented the highest adhesion level. The host and tissue specificity might also involve several other bacterial and host determinants important in vivo (Mundy et al., 2007; Ho et al., 2008; Xicohtencatl-Cortes et al., 2009). As previously reported for the lpfoperons, their expression could be controlled by a tightly regulated process, depending on gastrointestinal conditions such as bile salts (Torres et al., 2007; Chassaing et al., 2013), rendering the role of Lpf difficult to establish during binding to epithelial cells.

Taken together, our data showed that it is very difficult to assess STEC virulence and ability to cause outbreaks in these models, and that in vitro adherence may not be an accurate reflection of molecular interactions that occur between STEC and human colonic epithelium in vivo. Developing more appropriate models to study the mechanisms of the first colonization steps would help in designing novel therapeutic approaches to EHEC infection.

\section{AUTHOR CONTRIBUTIONS}

Conceived and designed the experiments: NP, LEM, VL. Performed the experiments: NP, LEM, JT, CC. Analyzed the data: NP, LEM, VL. Contributed reagents/materials/analysis tools: SBD, VL. Wrote the paper: NP, LEM, VL.

\section{ACKNOWLEDGMENTS}

We thank Marlène Ajalbert and Muriel Millet for their help during adhesion experiments. We thank Christelle Blavignac from the Centre Imagerie Cellulaire Santé for Microscopy experiments. This study was supported by Université d'Auvergne, and grants from MESR, INSERM, INRA, and Région Auvergne.

\section{REFERENCES}

Beutin, L. (2006). Emerging enterohaemorrhagic Escherichia coli, causes and effects of the rise of a human pathogen. J. Vet. Med. B Infect. Dis. Vet. Public Health 53, 299-305. doi: 10.1111/j.1439-0450.2006.00968.x

Bielaszewska, M., Mellmann, A., Zhang, W., Kock, R., Fruth, A., Bauwens, A., et al. (2011). Characterisation of the Escherichia coli strain associated with an outbreak of haemolytic uraemic syndrome in Germany, 2011: a microbiological study. Lancet Infect. Dis. 11, 671-676. doi: 10.1016/S1473-3099(11)70165-7

Cergole-Novella, M. C., Nishimura, L. S., Dos Santos, L. F., Irino, K., Vaz, T. M., Bergamini, A. M., et al. (2007). Distribution of virulence profiles related to new toxins and putative adhesins in Shiga toxin-producing Escherichia coli isolated from diverse sources in Brazil. FEMS Microbiol. Lett. 274, 329-334. doi: 10.1111/j.1574-6968.2007.00856.x

Chassaing, B., Etienne-Mesmin, L., Bonnet, R., and Darfeuille-Michaud, A. (2013). Bile salts induce long polar fimbriae expression favouring Crohn's diseaseassociated adherent-invasive Escherichia coli interaction with Peyer's patches. Environ. Microbiol. 15, 355-371. doi: 10.1111/j.1462-2920.2012.02824.x

Chong, Y., Fitzhenry, R., Heuschkel, R., Torrente, F., Frankel, G., and Phillips, A. D. (2007). Human intestinal tissue tropism in Escherichia coli O157: H7-initial colonization of terminal ileum and Peyer's patches and minimal colonic adhesion ex vivo. Microbiology 153, 794-802. doi: 10.1099/mic.0.2006/003178-0

Clements, A., Young, J. C., Constantinou, N., and Frankel, G. (2012). Infection strategies of enteric pathogenic Escherichia coli. Gut Microbes 3, 71-87. doi: 10.4161/gmic. 19182

Doughty, S., Sloan, J., Bennett-Wood, V., Robertson, M., Robins-Browne, R. M., and Hartland, E. L. (2002). Identification of a novel fimbrial gene cluster related to long polar fimbriae in locus of enterocyte effacement-negative strains of enterohemorrhagic Escherichia coli. Infect. Immun. 70, 6761-6769. doi: 10.1128/IAI.70.12.6761-6769.2002

Etienne-Mesmin, L., Chassaing, B., Sauvanet, P., Denizot, J., Blanquet-Diot, S., Darfeuille-Michaud, A., et al. (2011a). Interactions with $\mathrm{M}$ cells and macrophages as key steps in the pathogenesis of enterohemorrhagic Escherichia coli infections. PLoS ONE 6:e23594. doi: 10.1371/journal.pone.0023594

Etienne-Mesmin, L., Livrelli, V., Privat, M., Denis, S., Cardot, J. M., Alric, M., et al. (2011b). Effect of a new probiotic Saccharomyces cerevisiae strain on survival of Escherichia coli O157:H7 in a dynamic gastrointestinal model. Appl. Environ. Microbiol. 77, 1127-1131. doi: 10.1128/AEM.02130-10

Fitzhenry, R., Dahan, S., Torres, A. G., Chong, Y., Heuschkel, R., Murch, S. H., et al. (2006). Long polar fimbriae and tissue tropism in Escherichia coli O157:H7. Microbes Infect. 8, 1741-1749. doi: 10.1016/j.micinf.2006.02.012

Fitzhenry, R. J., Pickard, D. J., Hartland, E. L., Reece, S., Dougan, G., Phillips, A. D., et al. (2002). Intimin type influences the site of human intestinal mucosal colonisation by enterohaemorrhagic Escherichia coli O157:H7. Gut 50, 180-185. doi: 10.1136/gut.50.2.180

Frank, C., Werber, D., Cramer, J. P., Askar, M., Faber, M., An Der Heiden, M., et al. (2011). Epidemic profile of Shiga-toxin-producing Escherichia coli O104:H4 outbreak in Germany. N. Engl. J. Med. 365, 1771-1780. doi: 10.1056/NEJMoa1106483

Girardeau, J. P., Dalmasso, A., Bertin, Y., Ducrot, C., Bord, S., Livrelli, V., et al. (2005). Association of virulence genotype with phylogenetic background in comparison to different seropathotypes of Shiga toxin-producing Escherichia coli isolates. J. Clin. Microbiol. 43, 6098-6107. doi: 10.1128/JCM.43.12.6098-6107.2005

Golan, L., Gonen, E., Yagel, S., Rosenshine, I., and Shpigel, N. Y. (2011). Enterohemorrhagic Escherichia coli induce attaching and effacing lesions and hemorrhagic colitis in human and bovine intestinal xenograft models. Dis. Model. Mech. 4, 86-94. doi: 10.1242/dmm.005777

Hayward, R. D., Leong, J. M., Koronakis, V., and Campellone, K. G. (2006). Exploiting pathogenic Escherichia coli to model transmembrane receptor signalling. Nat. Rev. Micro. 4, 358-370. doi: 10.1038/nrmicro1391

Ho, T. D., Davis, B. M., Ritchie, J. M., and Waldor, M. K. (2008). Type 2 secretion promotes enterohemorrhagic Escherichia coli adherence and intestinal colonization. Infect. Immun. 76, 1858-1865. doi: 10.1128/IAI.01688-07

Hussein, H. S. (2007). Prevalence and pathogenicity of Shiga toxin-producing Escherichia coli in beef cattle and their products. J. Anim. Sci. 85, E63-E72. doi: 10.2527/jas.2006-421

Karmali, M. A., Mascarenhas, M., Shen, S., Ziebell, K., Johnson, S., Reid-Smith, R., et al. (2003). Association of genomic O island 122 of Escherichia coli EDL 933 with verocytotoxin-producing Escherichia coli seropathotypes that are linked to epidemic and/or serious disease. J. Clin. Microbiol. 41, 4930-4940. doi: 10.1128/JCM.41.11.4930-4940.2003

Knutton, S., Baldwin, T., Williams, P. H., and Mcneish, A. S. (1989). Actin accumulation at sites of bacterial adhesion to tissue culture cells: basis of a new diagnostic test for enteropathogenic and enterohemorrhagic Escherichia coli. Infect. Immun. 57, 1290-1298.

Li, Z., Elliott, E., Payne, J., Isaacs, J., Gunning, P., and O'loughlin E, V. (1999). Shiga toxin-producing Escherichia coli can impair T84 cell structure and function without inducing attaching/effacing lesions. Infect. Immun. 67, 5938-5945.

Mahajan, A., Currie, C. G., Mackie, S., Tree, J., Mcateer, S., Mckendrick, I., et al. (2009). An investigation of the expression and adhesin function of H7 flagella in the interaction of Escherichia coli O157: H7 with bovine intestinal epithelium. Cell. Microbiol. 11, 121-137. doi: 10.1111/j.1462-5822.2008. 01244.x

Mallick, E. M., Mcbee, M. E., Vanguri, V. K., Melton-Celsa, A. R., Schlieper, K., Karalius, B. J., et al. (2012). A novel murine infection model for Shiga toxinproducing Escherichia coli. J. Clin. Invest. 122, 4012-4024. doi: 10.1172/JCI62746 McKee, M. L., and O'Brien, A. D. (1995). Investigation of enterohemorrhagic Escherichia coli $\mathrm{O} 157: \mathrm{H} 7$ adherence characteristics and invasion potential reveals a new attachment pattern shared by intestinal E. coli. Infect. Immun. 63, 2070-2074. Mundy, R., Schuller, S., Girard, F., Fairbrother, J. M., Phillips, A. D., and Frankel, G. (2007). Functional studies of intimin in vivo and ex vivo: implications for host specificity and tissue tropism. Microbiology 153, 959-967. doi: 10.1099/mic.0.2006/003467-0

Naylor, S. W., Low, J. C., Besser, T. E., Mahajan, A., Gunn, G. J., Pearce, M. C., et al. (2003). Lymphoid follicle-dense mucosa at the terminal rectum is the principal site of colonization of enterohemorrhagic Escherichia coli O157:H7 in the bovine host. Infect. Immun. 71, 1505-1512. doi: 10.1128/IAI.71.3.1505-1512.2003 
Nicholls, L., Grant, T. H., and Robins-Browne, R. M. (2000). Identification of a novel genetic locus that is required for in vitro adhesion of a clinical isolate of enterohaemorrhagic Escherichia coli to epithelial cells. Mol. Microbiol. 35, 275-288. doi: 10.1046/j.1365-2958.2000.01690.x

Paton, J. C., and Paton, A. W. (1998). Pathogenesis and diagnosis of Shiga toxinproducing Escherichia coli infections. Clin. Microbiol. Rev. 11, 450-479.

Phillips, A. D., Navabpour, S., Hicks, S., Dougan, G., Wallis, T., and Frankel, G. (2000). Enterohaemorrhagic Escherichia coli O157:H7 target Peyer's patches in humans and cause attaching/effacing lesions in both human and bovine intestine. Gut 47, 377-381. doi: 10.1136/gut.47.3.377

Pradel, N., Bertin, Y., Martin, C., and Livrelli, V. (2008). Molecular analysis of shiga toxin-producing Escherichia coli strains isolated from hemolytic-uremic syndrome patients and dairy samples in France. Appl. Environ. Microbiol. 74, 2118-2128. doi: 10.1128/AEM.02688

Pradel, N., Leroy-Setrin, S., Joly, B., and Livrelli, V. (2002). Genomic subtraction to identify and characterize sequences of Shiga toxin-producing Escherichia col O91:H21. Appl. Environ. Microbiol. 68, 2316-2325. doi: 10.1128/AEM.68.5.23162325.2002

Pradel, N., Livrelli, V., De Champs, C., Palcoux, J. B., Reynaud, A., Scheutz, F., et al (2000). Prevalence and characterization of Shiga toxin-producing Escherichia col isolated from cattle, food, and children during a one-year prospective study in France. J. Clin. Microbiol. 38, 1023-1031.

Rangel, J. M., Sparling, P. H., Crowe, C., Griffin, P. M., and Swerdlow, D. L. (2005). Epidemiology of Escherichia coli O157:H7 outbreaks, United States, 1982-2002. Emerg. Infect. Dis. 11, 603-609. doi: 10.3201/eid1104.040739

Szalo, I. M., Goffaux, F., Pirson, V., Piérard, D., Ball, H., and Mainil, J. (2002). Presence in bovine enteropathogenic (EPEC) and enterohaemorrhagic (EHEC) Escherichia coli of genes encoding for putative adhesins of human EHEC strains. Res. Microbiol. 153, 653-658. doi: 10.1016/S0923-2508(02)01379-7

Tarr, P. I., Bilge, S. S., Vary, J. C. Jr., Jelacic, S., Habeeb, R. L., Ward, T. R., et al. (2000). Iha: a novel Escherichia coli O157:H7 adherence-conferring molecule encoded on a recently acquired chromosomal island of conserved structure. Infect. Immun. 68, 1400-1407. doi: 10.1128/IAI.68.3.1400-1407.2000

Tarr, P. I., Neill, M. A., Clausen, C. R., Newland, J. W., Neill, R. J., and Moseley, S. L. (1989). Genotypic variation in pathogenic Escherichia coli O157:H7 isolated from patients in Washington, 1984-1987. J. Infect. Dis. 159, 344-347. doi: 10.1093/infdis/159.2.344

Thevenot, J., Etienne-Mesmin, L., Denis, S., Chalancon, S., Alric, M., Livrelli, V., et al. (2013). Enterohemorrhagic Escherichia coli O157:H7 survival in an in vitro model of the human large intestine and interactions with probiotic yeasts and resident microbiota. Appl. Environ. Microbiol. 79, 1058-1064. doi: 10.1128/AEM.03303-12

Toma, C., Martinez Espinosa, E., Song, T., Miliwebsky, E., Chinen, I., Iyoda, S., et al. (2004). Distribution of putative adhesins in different seropathotypes of Shiga toxin-producing Escherichia coli. J. Clin. Microbiol. 42, 4937-4946. doi: 10.1128/JCM.42.11.4937-4946.2004
Torres, A. G., Milflores-Flores, L., Garcia-Gallegos, J. G., Patel, S. D., Best, A., La Ragione, R. M., et al. (2007). Environmental regulation and colonization attributes of the long polar fimbriae (LPF) of Escherichia coli O157:H7. Int. J. Med. Microbiol. 297, 177-185. doi: 10.1016/j.ijmm.2007.01.005

Trachtman, H., Austin, C., Lewinski, M., and Stahl, R. A. (2012). Renal and neurological involvement in typical Shiga toxin-associated HUS. Nat. Rev. Nephrol. 8, 658-669. doi: 10.1038/nrneph.2012.196

Winsor, D. K. Jr., Ashkenazi, S., Chiovetti, R., and Cleary, T. G. (1992). Adherence of enterohemorrhagic Escherichia coli strains to a human colonic epithelial cell line (T84). Infect. Immun. 60, 1613-1617.

Xicohtencatl-Cortes, J., Monteiro-Neto, V., Ledesma, M. A., Jordan, D. M., Francetic, O., Kaper, J. B., et al. (2007). Intestinal adherence associated with type IV pili of enterohemorrhagic Escherichia coli O157:H7. J. Clin. Invest. 117, 3519-3529. doi: 10.1172/JCI30727

Xicohtencatl-Cortes, J., Monteiro-Neto, V., Saldana, Z., Ledesma, M. A., Puente, J. L., and Giron, J. A. (2009). The type 4 pili of enterohemorrhagic Escherichia coli $\mathrm{O} 157: \mathrm{H} 7$ are multipurpose structures with pathogenic attributes. J. Bacteriol. 191, 411-421. doi: 10.1128/JB.01306-08

Xicohtencatl-Cortes, J., Saldana, Z., Deng, W., Castaneda, E., Freer, E., Tarr, P. I., et al. (2010). Bacterial macroscopic rope-like fibers with cytopathic and adhesive properties. J. Biol. Chem. 285, 32336-32342. doi: 10.1074/jbc.M110.162248

Yamamoto, T., Wakisaka, N., Sato, F., and Kato, A. (1997). Comparison of the nucleotide sequence of enteroaggregative Escherichia coli heat-stable enterotoxin 1 genes among diarrhea-associated Escherichia coli. FEMS Microbiol. Lett. 147, 89-95. doi: 10.1111/j.1574-6968.1997.tb10225.x

Conflict of Interest Statement: The authors declare that the research was conducted in the absence of any commercial or financial relationships that could be construed as a potential conflict of interest.

Received: 12 December 2014; accepted: 10 Febuary 2015; published online: 27 February 2015.

Citation: Pradel N, Etienne-Mesmin L, Thévenot J, Cordonnier C, BlanquetDiot $S$ and Livrelli $V$ (2015) In vitro adhesion properties of Shiga toxin-producing Escherichia coli isolated from cattle, food, and humans. Front. Microbiol. 6:156. doi: 10.3389/fmicb.2015.00156

This article was submitted to Infectious Diseases, a section of the journal Frontiers in Microbiology.

Copyright (c) 2015 Pradel, Etienne-Mesmin, Thévenot, Cordonnier, Blanquet-Diot and Livrelli. This is an open-access article distributed under the terms of the Creative Commons Attribution License (CC BY). The use, distribution or reproduction in other forums is permitted, provided the original author(s) or licensor are credited and that the original publication in this journal is cited, in accordance with accepted academic practice. No use, distribution or reproduction is permitted which does not comply with these terms. 